\title{
Erratum to: Life Cycle Analyses and Resource Assessments
}

\author{
Karl Fredga, Karl-Göran Mäler
}

Published online: 15 October 2010

\section{Erratum to: AMBIO (2010) 39:36-41 \\ DOI 10.1007/s13280-010-0063-y}

The sixth paragraph in the section "A Systems Ecology View on Bioenergy/Biofuels" (page 37) contains two errors. The number of Tata Nano small cars should have been (a) 5,000,000 and not 500,000 and (b) expressed as an estimate of what was potentially going to happen, not what already happened.

Therefore, the sixth paragraph should be changed to:

“A Hummer is a big, heavy car which costs 45,000 USD and consumes lots of fuel while Tata Nano is a small car developed in India, which costs 2,500 USD and needs very little fuel. Which car will generate most harm to the atmosphere in terms of emissions? Assume Tata Nano (and similar small cars) is purchased by $5,000,000$ people in
India and China followed by new roads, parking places, traffic lights, and garages. Two per cent of the arable land would be taken over for this purpose, leading to increased lack of food. The best way to avoid these kinds of problems is to abandon private car transportation and stimulate public transports."

\section{Karl Fredga $(\varangle)$}

Address: Energy Committee of the Royal Swedish Academy of Sciences, Stockholm, Sweden.

Address: Evolutionary Functional Genomics, EBC, Uppsala University, Uppsala, Sweden.

e-mail: karl.fredga@ebc.uu.se

\section{Karl-Göran Mäler}

Address: Energy Committee of the Royal Swedish Academy of Sciences, Stockholm, Sweden.

Address: The Beijer International Institute of Ecological Economics, Royal Swedish Academy of Sciences, Stockholm, Sweden.

e-mail:karl@beijer.kva.se

The online version of the original article can be found under doi: 10.1007/s13280-010-0063-y. 